\title{
LETTER
}

\section{Safety of dexmedetomidine sedation in postoperative cardiac surgery patients}

\author{
Fu-Shan Xue*, Yi Cheng and Rui-Ping Li \\ See related research by Lin et al., http://ccforum.com/content/16/5/R169
}

In a meta-analysis regarding efficacy and safety of dexmedetomidine sedation in postoperative cardiac surgery patients [1], Lin and colleagues' conclusion that dexmedetomidine may decrease the risk of hyperglycemia is questionable. In their meta-analysis of hyperglycemia in Figure 3 of their report, three articles regarding the use of dexmedetomidine sedation after cardiac surgery are cited [2-4]. In the study of Abd Aziz and colleagues [2], however, postoperative glucose level was not assessed as an end point. Shehabi and colleagues [3] showed that incidence of hyperglycemia (blood sugar level $>10 \mathrm{mmol} / \mathrm{L}$ ) was not significantly different between dexmedetomidine and morphine groups (36.8\% versus $47.6 \%, P=0.062)$. Herr and colleagues [4] demonstrated that the incidence of treatment-emergent hyperglycemia reaction was similar between dexmedetomidine and propofol groups (3\% versus $3 \%, P=0.750$ ). Furthermore, a recent meta-analysis indicates that dexmedetomidine does not decrease risk of hyperglycemia compared with the traditional sedative and analgesic agents in critically ill adult patients [5]. Thus, we are concerned about this incorrect conclusion of Lin and colleagues on the effect of dexmedetomidine on blood glucose level.

Actually, there is evidence in the literature indicating that dexmedetomidine can induce hyperglycemia, mediated via postsynaptic $\alpha_{2}$ adrenoreceptors located on pancreatic $\beta$ cells with a reduction of insulin secretion $[6,7]$. Even clinical studies show that dexmedetomidine can increase blood glucose level during minimally invasive video gynecologic surgical procedures [8] and cause hypoinsulinemia in postoperative patients needing sedation in the intensive care unit [9]. Thus, the effect of dexmedetomidine on perioperative blood glucose is rather complex and the currently available data from meta-analyses of dexmedetomidine studies have not

\footnotetext{
*Correspondence: xuefushan@aliyun.com

Department of Anesthesiology, Plastic Surgery Hospital, Chinese Academy of Medical Sciences and Peking Union Medical College, 33 Ba-Da-Chu Road, Shi-JingShan District, Beijing, People's Republic of China 100144
}

addressed this issue. We argue that further large randomized controlled trials are needed to obtain conclusive evidence and for determining the best choice among different therapeutic options.

\section{Competing interests \\ The authors declare that they have no competing interests.}

\section{Acknowledgements}

Fu-Shan Xue carefully read the paper of Lin and colleagues and analyzed their data, suggested the comment points and drafted this manuscript; Yi Cheng and Rui-Ping Li carefully read the paper of Lin and colleagues and analyzed their data, and helped to write this manuscript. All authors have read and approved the final manuscript.

Published: 11 June 2013

\section{References}

1. Lin YY, He B, Chen J, Wang ZN: Can dexmedetomidine be a safe and efficacious sedative agent in post-cardiac surgery patients? a metaanalysis. Crit Care 2012, 16:R169.

2. Abd Aziz N, Chue MC, Yong CY, Hassan Y, Awaisu A, Hassan J, Kamarulzaman $\mathrm{MH}$ : Efficacy and safety of dexmedetomidine versus morphine in postoperative cardiac surgery patients. Int J Clin Pharm 2011, 33:150-154.

3. Shehabi Y, Grant P, Wolfenden H, Hammond N, Bass F, Campbell M, Chen J: Prevalence of delirium with dexmedetomidine compared with morphine based therapy after cardiac surgery: a randomized controlled trial (DEXmedetomidine COmpared to Morphine-DEXCOM Study). Anesthesiology 2009, 111:1075-1084.

4. Herr DL, Sum-Ping ST, England M: ICU sedation after coronary artery bypass graft surgery: dexmedetomidine-based versus propofol-based sedation regimens. J Cardiothorac Vasc Anesth 2003, 17:576-584.

5. Tan JA, Ho KM: Use of dexmedetomidine as a sedative and analgesic agent in critically ill adult patients: a meta-analysis. Intensive Care Med 2010, 36:926-939.

6. Pypendop BH, Barter LS, Stanley SD, IIkiw JE: Hemodynamic effects of dexmedetomidine in isoflurane-anesthetized cats. Vet Anaesth Analg 2011, 38:555-567.

7. Restitutti F, Raekallio M, Vainionpää M, Kuusela E, Vainio O: Plasma glucose, insulin, free fatty acids, lactate and cortisol concentrations in dexmedetomidine-sedated dogs with or without MK-467: a peripheral $a-2$ adrenoceptor antagonist. Vet J 2012, 193:481-485.

8. Bulow NM, Barbosa NV, Rocha JB: Opioid consumption in total intravenous anesthesia is reduced with dexmedetomidine: a comparative study with remifentanil in gynecologic videolaparoscopic surgery. J Clin Anesth 2007, 19:280-285.

9. Venn RM, Bryant A, Hall GM, Grounds RM: Effects of dexmedetomidine on adrenocortical function, and the cardiovascular, endocrine and inflammatory responses in post-operative patients needing sedation in the intensive care unit. Br J Anaesth 2001, 86:650-656.

doi:10.1186/cc12724

Cite this article as: Xue FS, et al:: Safety of dexmedetomidine sedation in postoperative cardiac surgery patients. Critical Care 2013, 17:435. 